\title{
Anomalous Traces in the Cone of Equisetum maximum, Lam.
}

\author{
BY
}

\section{ISABEL M. P. BROWNE.}

T $\mathrm{N}$ an account of the anatomy of the cone of Equisetum maximum, Lam., published in I9I5, a brief comment was made on the abnormal behaviour of certain traces of a cone of this species (Browne, I9I5, pp. 2478). Since I9I5 numerous facts concerning anomalies in the course and structure of the traces of the sporangiophores of $E$. maximum have come under my notice, and I propose to give a short account of the phenomena observed.

The anomalies about to be described are of three kinds.

In the first or A anomaly the phloem of the trace enters into connexion with that of the axis, and the tracheides of the trace enter the bundle but, failing to join on to the axial protoxylem, die out among the metaxylem elements.

A second anomalous type of trace is that in which the phloem joins on to the phloem of the axial bundle, though the tracheides of the trace do not penetrate the bundle, but die out in the cortex. This kind of anomaly I propose to call the $\mathrm{B}$ anomaly.

The third anomaly is the most striking of those about to be considered and is that mentioned in my paper of I9I5. A trace, passing in from a sporangiophore, dies out in the cortex without any of its elements joining on to the corresponding elements of the axial bundle. Such a trace may conveniently be called a free trace, or a trace showing the $\mathrm{C}$ anomaly.

These three kinds of anomaly are not confined to the traces of the lowest whorl of the cone of $E$. maximum, but they are much more frequent in that position. Consequently, in order to obtain reliable data as to these anomalous traces, I have made a detailed study of the traces of the lowest whorl in four cones of E. maximum. Two of these cones are those already described in my paper of I9I 5 as Cones $A$ and $B$; the two others have never been described and $\mathrm{I}$ propose to refer to them as Cones $\mathrm{F}$ and $\mathrm{G}$.

[Annals of Botany, Vol. XXXVII. No. CXLVIII. October, 1923.] 
The following table gives the particulars as to the number of vascular strands, normal and anomalous, entering the axis from the sporangiophores in the lowest whorls of the four cones studied.

$\begin{array}{ccccc}\begin{array}{c}\text { Lowest whorl } \\ \text { of cone. }\end{array} & \begin{array}{c}\text { Strands showing } \\ \text { the A anomaly. }\end{array} & \begin{array}{c}\text { Strands showing } \\ \text { the B anomaly. }\end{array} & \begin{array}{c}\text { Strands showing } \\ \text { the C anomaly. }\end{array} & \begin{array}{c}\text { Normal } \\ \text { strands. }\end{array} \\ \text { A } & 2 & 0 & 4 & \text { I } 8 \\ \text { B } & \text { I } & 0 & 0 & 4 \text { I } \\ \text { F } & 7 & 4 & 14 & 5 \\ \text { G } & 6 & \text { I } & 0 & 20\end{array}$

As already pointed out these anomalous traces also occur, though more rarely, in other positions and in the cones of other species. For instance, in the upper part of Cone A of E. maximum one of the strands belonging to a sporangiophore of the twelfth whorl died out in the cortex. So did one of the strands entering the cortex from a bifascicular sporangiophore of the second whorl of a cone of E. sylvaticum (Browne, I92I, p. 438). The $\mathrm{B}$ anomaly seems to be rather rare. Besides the cases recorded in the above table I have observed a case in which a vascular strand entering the cortex from a bifascicular sporangiophore of the sixth whorl of Cone $\mathrm{F}$ of E. maximum showed this peculiarity. The sporangiophore was, to judge from its size and form, single in nature, but peculiar in that its two vascular strands were vertically superposed, the upper one showing the B anomaly and the other, which originated about $200 \mu$ lower down, the $\mathrm{C}$ anomaly. The $\mathrm{B}$ anomaly has also been observed in a cone of $E$. limosum (Browne, I915, p. 248), and once in a cone of E. sylvaticum (Browne, I92I, p. 438).

It might be supposed that the A anomaly would be commoner than the $\mathrm{B}$ and $\mathrm{C}$ anomalies, since it shows a less great departure from the normal than these. I have, however, only observed it in E. maximum. In the case of Cone $\mathrm{F}$ there were, besides the seven cases in the lowest whorl included in the above table, seven other examples of the A anomaly. All were situated in the lower half of the cone, since they did not occur above the level of the seventh whorl, at which level there were three of them. In the five lowest whorls of Cone $\mathrm{G}$ - the portion of this cone studied for the present purpose-there were six strands of this type belonging to sporangiophores of the lowest whorl and one to a sporangiophore of the fourth whorl. It should be borne in mind that the $\mathrm{A}$ anomaly is much less obvious than either of the other two anomalies and requires careful and prolonged examination to distinguish it from the normal type. Discontinuity between the axial protoxylem and that entering the stele from a sporangiophore can only be established when the series of sections is complete and the preservation of the tissues good. In the case of the $\mathrm{A}$ anomalies described in this paper I was, however, able to satisfy myself of the real discontinuity between the axial protoxylem and that entering the stele from the sporangiophores. In view of the difficulties and lengthiness of the process of distinguishing those traces showing the A anomaly from normal traces, and in view also of the 
essentially similar results obtained from a study of the lowest whorls of Cones A, B, F, and G of E. maximum, I did not attempt to make a detailed study of the attachment of the xylem of the traces to the protoxylem of the stele throughout the whole of Cones $\mathrm{A}, \mathrm{B}$, and $\mathrm{G}$, although this was done for Cone F.

Before further considering these anomalous traces it may be well briefly to recall certain points as to the normal traces of the sporangiophores of E. maximum. As is usually the case in the genus the xylem of the traces of the sporangiophores is given off from the axial protoxylem. The traces of the lowest whorl, and to a less degree those of several of the succeeding whorls, are constantly deflected downwards as they pass outwards through the cortex. This deflexion is especially marked at maturity. In Cone $B$, which was mature, the average downward divergence of the traces of the lowest whorl was $997 \mu$, and in one case the extent of the downward deflexion reached $1,500 \mu$. A similar downward divergence, often varying considerably in extent, is characteristic of anomalous as well as of normal traces in the lower region of the cone.

As a result of the unequal downward deflexion of the traces in the cortex the difference of level between the traces at their insertion on the stele is often greater than the difference in level between the sporangiophores that they supply, and in some cases is sufficient to make it doubtful in examining reconstructions of the stele of the cone to which whorl certain traces belong. It is interesting to note that a similarly variable course is characteristic also of the protoxylem destined to the sporangiophore during its passage through the axial bundle. This feature is not shown in either of my reconstructions of the steles of Cones $\mathrm{A}$ and $\mathrm{B}$ of $\mathrm{E}$. maximum, since they show the distribution of the xylem generally without indicating the course of the protoxylem (Browne, I9I 5, Pl. XII and Pl. XIII). The protoxylem destined to pass out as the xylem of a trace may become detached from a (relatively) main axial protoxylem strand at the height at which it passes out of the bundle or considerably above or below this level. For example, taking the group of protoxylem strands that pass out as portions of the traces $7-\mathrm{I} 3$ of the lowest whorl of Cone A (see Browne, I9 I $5, \mathrm{Pl}$. XII), we find that the protoxylem supplying the seventh and eighth traces of the diagram is given off slightly above the point at which it makes its exit from the bundle. In other words, the tracheides of the trace are slightly deflected within the bundle. Those composing the protoxylem of the ninth and twelfth traces are more markedly deflected within the bundle, while those of the tenth and thirteenth traces pass outwards through the bundle in an upward direction, the former becoming free $750 \mu$ and the latter $280 \mu$ higher up. The course of the protoxylem of the eleventh trace is highly suggestive. This trace shows the A anomaly, for the protoxylem of the incoming trace does not unite with that of the axis. Its elements run 
steeply upwards and inwards within the bundle until they are separated from the axial protoxylem by but a single parenchymatous cell. Their number then rapidly decreases and they soon die out, so that the connexion is not effected. One of the traces of the sixth whorl of Cone F of E. maximum was interesting because it appeared to be intermediate between the trace just described and normal traces. In it all the tracheides of the incoming trace died out in the metaxylem of the bundle, except one which joined on to the axial protoxylem. It should be borne in mind that whether the protoxylem of the traces of the lowest whorls of cones of $E$. maximum passes out more or less horizontally or upwards or downwards through the bundle, it is always deflected downwards in its passage through the cortex.

The extent to which the protoxylem of a trace may be deflected within the bundle is variable. In Cone $B$, in which the axis of the cone had elongated fully, the deflexion was sometimes as much as $420 \mu$. This was, of course, exclusive of the usually much greater deflexion of the trace in the cortex. Though on the whole greatest in the lowest whorls the deflexion within the bundle of the protoxylem that is about to depart is not confined to these whorls. Cases of a downward deflexion within the bundle of over I $50 \mu$ were observed to occur at the level of the fourth and fifth whorls of Cone G.

The cases in which the protoxylem destined to the trace passes upwards and outwards through the bundle seem to be examples of an early preparation for the departure of the trace. They are by no means confined to the region of the lowest or lower whorls. I have observed cases in which a small canal, left by the destruction of the protoxylem elements, separated from a relatively main protoxylem canal of the axis about $2 \mathrm{~mm}$. below its departure from the bundle. So great a distance between the separation of the protoxylem of the trace and its departure from the bundle is very exceptional. Quite often, however, the distance is between 0.5 and $0.75 \mathrm{~mm}$.

As the metaxylem was still undifferentiated at the time at which the tracheides of the trace were undergoing lignification, traces showing the A anomaly afford examples of a disjunction between the vascular system of the axis and that of some of the appendages. This isolation of appendicular protoxylem is to a large extent remedied later by the development of axial metaxylem round the incoming protoxylem. It should, however, be borne in mind that in this species the metaxylem remains separated from the more deeply seated protoxylem (Barratt, pp. 223-4; Browne, I92I, p. 447).

We may, I think, see in this separation of protoxylem and metaxylem in the cone of E. maximum a feature correlated with the presence in this species of the A anomaly. In other words, it is suggested that the inconvenient depth of the axial protoxylem in the lower part of the cone may. have increased the number of cases in which the xylem of the sporangiophore fails to enter into connexion with the protoxylem of the axis. It is 
true that separation of protoxylem and metaxylem, though less constant than in the cone of E. maximum, is characteristic also of the cone of $E$. arvense, in which the $\mathrm{A}$ anomaly has not been observed. But, apart from the inconspicuousness of the anomaly, which may have led to its being overlooked, the actual distance between metaxylem and protoxylem is markedly greater in E. maximum than in E. arvense, and is especially considerable in the lower part of the cone of the former species, in which region the A anomaly seems chiefly to occur.

At the same time, though the depth of the axial protoxylem may have led to an increase in the number of cases in which the protoxylem of the sporangiophore fails to enter into connexion with that of the axis, it is clear that the xylem of the incoming trace shows, in E. maximum, a tendency towards reduction in the inner part of its course. For in the second or $\mathrm{B}$ anomaly the tracheides of the trace do not even enter the bundle. This very obviously represents a further stage in the reduction of the protoxylem of the trace within the axis of the cone. In this type of trace the phloem has not suffered any reduction.

In the third or C type of anomaly-in the free trace-the reduction in the course of the trace in the axis is carried still farther. The phloem as well as the xylem ceases to be formed over a part of the course normally traversed by traces. In some cases the free strands of the sporangiophores approach very close to the stele; in other cases they die out at the base of the sporangiophore without penetrating into the cortex.

I have examined twenty examples of vascular strands belonging to sporangiophores which failed to reach the axial stele, five in Cone A and fourteen in Cone $\mathrm{F}$ of $E$. maximum, and one belonging to a cone of E. sylvaticum. In two cases only, both in E. maximum, did the free bundle die out without entering the cortex. Of the eighteen other free strands some only died out when they had approached very close to the axial stele, and others died out almost as soon as they entered the cortex. A series could have been constructed showing traces dying out at every depth in the cortex. In E. maximum it is quite common for the individual tracheides of the free traces to become markedly wider (often about twice as wide) before they die out. Barratt has shown that in the cone of $E$. palustre the first tracheide of the trace to be differentiated abuts on the axial protoxylem and that the further differentiation of the tracheides proceeds outwards into the stalk of the sporangiophore (Barratt, p. 223 and Text-figure I9, p. 222). The enlargement of the tracheides before the dying out of the free trace suggests the possibility that, at least in the lowest whorl of the cone of E. maximum, the differentiation of the tracheides of the trace may begin in the distal part of the latter's course and proceed inwards. On the other hand, any marked increase in the width of the tracheides as we pass inwards is not a feature of the normal traces. In this connexion it may be pointed out that should 
such a difference as that suggested above be found to exist it might, perhaps, be brought into relation with the fact that in the cones of E. palustre the downward deflexion of the traces of the sporangiophores in the cortex is insignificant even in mature cones and at the level of the lowest whorl ; while in the cone of E. maximum a downward deflexion of the traces in the cortex is characteristic of the cone, at the level of the lowest whorl, even of very young specimens, and possibly exists even at the moment of lignification of the tracheides of these traces (Browne, I9I 5 , p. 247).

Cone $\mathrm{B}$ of E. maximum possessed no free traces. Some, however, of the traces of the lowest whorl, e.g. Nos. 5,36 , and 40 of this whorl in my diagrammatic reconstruction of the stele (Browne, Pl. XII I, I9 I5), appeared, as they entered the axis from the sporangiophore, to be approximately twice as large as the average traces. These traces rapidly diminished in size by the dying out of numerous tracheides in the cortex, and before reaching the axial stele they are indistinguishable in size from the other traces. They might be held to show preparation within the cortex for an early division of the trace in the sporangiophore. Two facts, however, suggest that these traces show a certain tendency towards a reduction in the inner part of their course through the cortex, though the tendency is not strong enough to lead to the development of a free trace. In the first place, these traces do not divide unusually early within the sporangiophore; secondly, the elements that die out as the trace passes inwards through the cortex (or make their appearance as it passes outwards) are aggregated chiefly on one side of the strand.

The presence of free strands and of other anomalous traces is frequently associated with the existence of bifascicular sporangiophores, apparently single in nature, and still more often with the prevalence of complexes consisting of two or several more or less concrescent sporangiophores. In the only case in which a free strand was observed in E. sylvaticum it was one of two strands entering the axis from a sporangiophore clearly single in nature. In Cone $\mathrm{A}$ of $E$. maximum four out of five free strands formed part of the vascular supply either of a sporangiophore single in nature but possessing two distinct bundles, or of a double sporangiophore, i. e. a sporangiophore formed by the concrescence of two sporangiophores. ${ }^{1}$ Only the last free trace in the diagram on the reader's right (cf. Browne, I9I 5, Pl. XII) represents the whole vascular supply of an ordinary monofascicular sporangiophore. In my first note on free traces, published in 1915 , three out of four free strands found at the level of the lowest whorl of Cone A of E. maximum were regarded as belonging to sporangiophores single in nature. On a careful re-examination of the sporangiophores of this whorl, however, I have

1 One of the free strands at the level of the lowest whorl is not shown in my reconstruction of the stele of Cone A of E. maximum (Browne, 1915, Pl. II), because it died ont within the sporangiophore. This strand was situated between the fifth and sixth traces of the diagram. 
come to the conclusion that two of these sporangiophores are double in nature and represent two concrescent members, while one is a single, unusually large, bifascicular sporangiophore.

The lowest whorl of Cone $\mathrm{F}$ of $E$. maximum, in which the free traces are more numerous than in any other whorl examined (fourteen out of thirty), shows an extraordinary degree of concresence among the sporangiophores. Only one of the free traces supplied a single, monofascicular sporangiophore. All the sporangiophores had very short stalks, so that their heads tended to be close together, a condition obviously favourable to concrescence. The stalks of the sporangiophores are often dilated at their insertion on the axis. This, coupled with the unusual shortness of their stalks, gives on superficial examination a fallacious impression that the sporangiophores are all slightly coherent basally. I have in the following paragraphs attempted to analyse the constitution of this whorl. The term complex is used throughout to denote a series of sporangiophores showing a considerable degree of concrescence. The presence in a complex of a given number of mutually independent vascular strands does not necessarily indicate that the complex is composed of a number of members equal to the strands. Bifascicular sporangiophores, single in nature, i.e. sporangiophores whose traces divide while still in the cortex, are common in E. maximum, and as such sporangiophores tend to be rather large they are inclined to be more closely approximated to their neighbours and more frequently fused with them. Thus bifascicular members are relatively common in complexes. On the other hand, there seems to be at least one possible case in which a more or less reduced or arrested member of a complex was devoid of a vascular strand (cf. under 10 of analysis). These two considerations introduce an element of difficulty, even of uncertainty, in analysing complexes. In the following section, however, I have indicated the only two cases in which I felt any doubt as to the number of constituents in a complex.

\section{Analysis of the lowest Whorl of Cone F of E. MAXIMUM.}

I. A complex of four sporangiophores. This is supplied by a normal trace, two free traces, and another normal trace. This complex is locally concrescent (over the middle region of the stalk and part of the head) with :

2. A single, monofascicular sporangiophore. This sporangiophore is followed by:

3. A complex of two sporangiophores. The first and largest member contains two closely approximated vascular strands, one a free strand and the other showing the B anomaly. The second sporangiophore of the complex contains a free strand. This complex is followed by :

4. A complex of three sporangiophores. The first member possesses 
a free trace, the middle and largest member two closely approximated strands, one free and the other showing the A anomaly. The third member also has a trace showing the A anomaly. This complex is followed by:

5. A still larger complex consisting possibly of three, more probably of four, almost completely fused sporangiophores. This is traversed, firstly, by a small, unbranched free strand, running only to the base of a single sporangium; next to this strand is a trace showing the A anomaly, and it seems doubtful whether these two belong to an unusually large bifascicular sporangiophore, or whether the lobe containing the small free strand represents a partially aborted sporangiophore. Beyond the trace showing the A anomaly are two free traces, clearly belonging to different, though almost completely concrescent sporangiophores. The traces of this complex run at different levels, but there are, nevertheless, levels at which the whole wide complex appears to possess no vascular strands. Coherent with this complex by the concrescence of the larger part of the surface of the stalk is :

6. Another complex consisting of two sporangiophores. The first sporangiophore is provided with a free trace and the other with a trace showing the $\mathrm{B}$ anomaly. This complex is followed by:

7. Four free, single and monofascicular sporangiophores. One of these possesses a free trace, two possess traces showing the A anomaly, and one a trace showing the B anomaly. The last of these sporangiophores is followed by :

8. A bifascicular sporangiophore which, though rather large, is clearly single in nature. One of its strands shows the A anomaly and the other the $\mathrm{B}$ anomaly. This sporangiophore is followed by:

9. A complex of three sporangiophores. The first and third members of this complex are supplied by traces showing the A anomaly, while the vascular supply of the middle member is a free trace. This complex is followed by :

10. A large complex of three or four sporangiophores. The first member of this complex is rather large and possesses two closely approximated vascular strands, one a free strand and the other showing the $\mathrm{B}$ anomaly. The second and third members each possess a free trace, and beyond the third is a considerable projection devoid of vascular strands, which might conceivably be regarded as the rudiment of a fourth sporangiophore.

This completes the analysis of the whorl.

\section{Theoretical Considerations.}

In a previous paper it has been argued that the distribution of the metaxylem of the cone of $E$. maximum indicated that in this species the vascular system of the cone had undergone reduction (Browne, I915, pp. 235-7). As has already been pointed out the $A, B$, and $C$ anomalies of 
the sporangiophoric traces, anomalies which are found especially frequently in E. maximum, indicate a certain reduction of the protoxylem system. It is not possible in the present publication to deal at all fully with the course of the strands of protoxylem in the axis. It may, however, be stated that a study of the course of this system reveals the occasional existence of protoxylem strands unconnected with the main axial system of protoxylem. Two such detached strands have already been recorded from the cone of E. sylvaticum (Browne, I92I, p. 454). Such cases can hardly have arisen except by the poor development of the protoxylem system. Below the insertion of the lowest whorls both of Cones $\mathrm{A}$ and $\mathrm{F}$ of $E$. maximum one of the protoxylem strands supplying a normal trace was found to terminate blindly $300-5 \mathrm{co} \mu$ lower down. Possibly a detailed study of Cones A and $B$ would yield other examples of protoxylem strands ending blindly in a downward direction, though no others were found in Cone $F$. In the lower region of Cone $\mathrm{G}$ - the only part studied - there were five axial strands of protoxylem with blind basal endings. In two cases strands of protoxylem which appear, as we pass upwards, to arise de novo in the metaxylem are so clearly in the line of continuation of the protoxylem that died out $300-500 \mu$ lower down that it is difficult not to regard them as separated from the main system by a local failure of certain cells to develop as tracheides. In neither of these cases did the main protoxylem strand pass out as a trace at the level of the next whorl of sporangiophores. On the contrary, these protoxylem strands were still pursuing their upward course when the series of sections came to an end and both had given off traces to members of several whorls. In another case a strand of this sort, which also persisted upwards beyond the end of the series of sections, passed through the level of two whorls before giving off a trace. Below the lowest whorl of this cone is a free strand of protoxylem, about $300 \mu$ long. The position of this strand is such that it has the appearance of being the continuation of one of the branches arising by a supra-annular forking of the protoxylem. The distance between it and one of these protoxylem branches is about $250 \mu$. These and other cases leave a very strong impression that the free axial strands of protoxylem do not represent an increase of protoxylem development, but arise rather by local failure of certain stelar cells to develop as tracheides.

\section{SUMMARY.}

I. The occurrence in cones of Equisetum maximum of traces of which the protoxylem, though entering the vascular bundle, fails to reach the axial protoxylem and dies out in the metaxylem; of other traces of which the phloem only enters into connexion with the corresponding tissues of the axis; and of yet other traces which die out completely in the cortex with- 
604 Browne.-Anomalous Traces in the Cone of E. maximum, Lam.

out coming into contact with the axial stele, seems to point to the existence of a progressive reduction of the vascular system. Since the xylem of the sporangiophores consists practically exclusively of protoxylem this reduction has chiefly affected the latter, though in some cases the phloem is also affected.

2. Evidence that a reduction of the protoxylem system has occurred is supplied by the occasional presence in the steles of the cones of E. maximum of strands of protoxylem ending blindly in a downward direction.

3. Though apparently commoner in cones of E. maximum than in those of other species the anomalies described above are not confined to this species.

\section{LITERATURE CITED.}

Barratt, K.: A Contribution to our Knowledge of the Vascular System of the Genus Equisetum. Ann. Bot., vol. xxxiv, pp. $201-35$, 1920.

Browne, I.: (I) A Second Contribution to our Knowledge of the Anatomy of the Cone and Fertile Stem of Equisetum. Ibid., vol. xxix, pp. 231-64, I9'5.

- : (2) A Fourth Contribution to our Knowledge of the Anatomy of the Cone and Fertile Stem of Equisetum. Ibid., vol. xxxv, pp. 427-56, I92I. 


\section{$2 \mathrm{BHL}$ Biodiversity Heritage Library}

Browne, Isabel. 1923. "Anomalous traces in the cone of Equisetum maximum, Lam." Annals of botany 37, 595-604.

https://doi.org/10.1093/oxfordjournals.aob.a089869.

View This Item Online: https://www.biodiversitylibrary.org/item/270686

DOI: https://doi.org/10.1093/oxfordjournals.aob.a089869

Permalink: https://www.biodiversitylibrary.org/partpdf/319105

\section{Holding Institution}

New York Botanical Garden, LuEsther T. Mertz Library

\section{Sponsored by}

BHL-SIL-FEDLINK

\section{Copyright \& Reuse}

Copyright Status: Public domain. The BHL considers that this work is no longer under copyright protection.

This document was created from content at the Biodiversity Heritage Library, the world's largest open access digital library for biodiversity literature and archives. Visit BHL at https://www.biodiversitylibrary.org. 